\title{
Controlled ovarian stimulation therapy as a potential risk for the development and progression of renal cell carcinomas: A case report and literature review
}

\author{
SOTIRIOS G. DOUKAS ${ }^{1,2}$, BORIS MARTINEZ ${ }^{1}$, MARNIE E. ROSENTHAL ${ }^{1}$ and DIMITRA P. VAGELI ${ }^{3}$ \\ ${ }^{1}$ Department of Medicine, Rutgers/Saint Peter's University Hospital, New Brunswick, NJ 08901, USA; \\ ${ }^{2}$ Department of Forensic Sciences and Laboratory of Toxicology, Medical School, \\ University of Crete, 71003 Heraklion, Greece; ${ }^{3}$ The Yale Larynx Laboratory, \\ Department of Surgery, Yale School of Medicine, New Haven, CT 06510, USA
}

Received January 23, 2021; Accepted May 11, 2021

DOI: $10.3892 / \mathrm{mco} .2021 .2302$

\begin{abstract}
Renal Cell Carcinoma (RCC) is the most common type of cancer in the kidney and is mostly asymptomatic. Previous studies have supported the important role of sex hormones in RCC pathophysiology and that targeted hormone receptor therapy, such as estrogen receptor targeting, is a promising treatment strategy. However, to the best of our knowledge, it remains unknown whether hormonal therapy, such as controlled ovarian stimulation for in vitro fertilization, serves a role in the development and progression of RCC. The present report describes a case of RCC developed after a fertility stimulation therapy and provides a summary of the known literature on the role of hormone receptors in the development and progression of RCC. A 35-year-old woman received fertility stimulation treatment with follitropin alfa 900 units, human chorionic gonadotropic hormone 5,000 units, injectable leuprolide $1 \mathrm{mg} / 0.2 \mathrm{ml}$ and cetrotide $0.25 \mathrm{mg}$. The patient presented to the hospital with shortness of breath and weight loss. The patient had no known genetic predisposition or family history of malignancies and no exposure to chemicals. The patient never used tobacco, alcohol or recreational drugs. Imaging revealed a 17x19 mm, heterogeneously enhancing, and partially exophytic mass in the right kidney. After partial nephrectomy, the pathological evaluation confirmed the diagnosis of clear cell RCC. To the best of our knowledge, this was the first time that a case of ovarian stimulation therapy was associated with the development of RCC. This case raises concerns about the potential oncogenic effect of controlled ovarian stimulation therapy in RCC promotion, suggesting a
\end{abstract}

Correspondence to: Dr Sotirios G. Doukas, Department of Medicine, Rutgers/Saint Peter's University Hospital, 254 Easton Avenue, New Brunswick, NJ 08901, USA

E-mail: sdoukas@saintpetersuh.com

Key words: in vitro fertilization, estrogens, renal cell carcinoma, ovarian stimulation therapy need for systematic research to clarify the clinical significance of existing pre-clinical data.

\section{Introduction}

Kidney cancers affect more than a million people worldwide, with an annual incidence of 400,000 cases per year. In 2018 kidney cancer was the 8th most common cancer in men $(634,383$ cases $)$ and the 12 th most common in women (391,347 cases). During the same year, 175,089 deaths were related to kidney cancer, accounting as the 16th cause of death from cancer worldwide (1). Although kidney cancer incidence has increased worldwide, improvements in mortality have been observed only in developed countries (2-4).

Most kidney cancers are RCC, of which clear cell RCC is the most common (70-85\% of cases), followed by papillary RCC (10\%) and chromophobe RCC $(5,6)$. Clear cell RCC are usually solitary and tend to invade the renal sinus structures, renal vein tributaries, and lymph nodes and possibly metastasize to the lungs, liver, adrenal glands, and brain $(5,6)$. Risk factors include obesity, active and passive cigarette smoking, hypertension, end-stage renal failure, long-term renal dialysis, while $2-3 \%$ are hereditary $(3,6)$.

More than half of all RCC are incidentally discovered during imaging. Patients who develop symptoms may present with flank pain, macroscopic hematuria, and palpable abdominal mass. Those with metastatic disease may experience with shortness of breath, headache, bone pain, or paraneoplastic syndromes (7). Given that most RCC are asymptomatic, the majority are diagnosed as incidental findings on imaging. CT and MRI of the abdomen are usually performed to evaluate the mass's characteristics and assess the metastasis that determines the tumor stage.

According to the National Health Survey of Family Growth, in the US between 2006-2010, among all women aged 15-44 and their partners, twelve percent had impaired fecundity and had used infertility services (8), with IVF used by 275,000 women aged 25-44 over the same period (9). IVF is a method used to treat infertility by combining hormone analogs to induce controlled ovarian stimulation for oocyte develop- 
ment (10). As a result of this treatment, multiple mature oocytes can be retrieved, fertilized in vitro, and implanted, increasing the chances of a live birth. In particular, and similar to our case, patients undergoing fertility stimulation therapy usually receive follitropin alfa, $\mathrm{HCG}$, leuprolide (injectable treatment), and cetrotide (11-14). Follitropin alfa, or follicle-stimulating hormone (FSH), is a hormone promoting the development and maturation of oocytes in the ovaries (11). HCG is a hormone that supports the maturation of follicles and promotes the release of estrogens from the luteal body (12). Leuprolide is a synthetic gonadotropin-releasing hormone $(\mathrm{GnRH})$ (13). Cetrotide is used to block the hormone GnRH to be released from the ovaries, regulating hormone responses in women during fertility treatments (14). Direct morbidity and mortality related to IVF are relatively low. Possible complications include ovarian hyperstimulation syndrome, thrombosis, infection, multiple pregnancies, allergic reactions, and anesthetic complications (15).

Recent studies comparing the risk of developing cancer between women undergoing controlled ovarian stimulation and the general population have not provided convincing evidence of an excessive risk for all gynecological cancers (16), including ovarian $(17,18)$ and breast cancer $(19,20)$. Little is known about the implications and possible associations of controlled ovarian stimulation and the development or progression of other solid tumors such as RCC.

Epidemiological and biochemical data show that Renal Cell Carcinoma (RCC) development and progression are associated with sex-hormone dysregulation (21). In this case, we describe the diagnosis of RCC in a nulliparous woman received controlled ovarian stimulation for in vitro fertilization (IVF). We aim to raise awareness of the potential oncogenic effect of hormonal therapy used for IVF and review the role of hormone receptors in the development and progression of RCC.

\section{Case report}

A 35-year-old nulliparous woman with no past medical history other than difficulty in conceiving received fertility stimulation therapy with follitropin alfa (900 Units), human chorionic gonadotropic hormone (HCG) (5,000 Units), leuprolide ( $1 \mathrm{mg} / 0.2 \mathrm{ml}$ injectable therapy), and cetrotide $0.25 \mathrm{mg}$. She was referred to the hospital to evaluate a three-day history of intermittent shortness of breath associated with stressful situations. She did not have chest pain, wheezing, cough, fever or chills, and had lost 3-5 pounds over the last two months. She did not use tobacco, alcohol, or recreational drugs, had no known exposure to chemicals, and had a negative family history of malignancies.

The patient's vital signs, laboratory values, and physical exam were generally non-revealing. Given the risk for thromboembolism, since the patient was on hormonal therapy, a Computed Tomographic Pulmonary Angiography (CTPA) was performed. Although no cardiopulmonary pathology was found, a 17x19 mm heterogeneously enhancing and partially exophytic mass was described in the right kidney. Subsequent abdominal Magnetic Resonance Imaging (MRI) better delineated an enhancing lesion with internal septations at the lateral aspect of the right kidney suspected for RCC. The patient underwent partial nephrectomy, and pathological evaluation confirmed the diagnosis of clear cell RCC.

\section{Discussion}

RCC's high incidence in men and the negative correlation between RCC and menarche age, hysterectomy, and high parity in women suggested that sex hormones play a role in RCC $(22,23)$. Most recent studies have shown that the pathophysiology of RCC and its progression are hormonally influenced via autocrine or paracrine modes. The RCC cells often express receptors, including gonadotropin-releasing hormone receptor (GnRHR), follicle-stimulating hormone receptor (FSHR), estrogen receptor (ER), androgen receptor (AR), and progesterone receptor (PR) $(21,24)$. AR positivity appears to be correlated with a better prognosis, however, more research is needed on its effects.

In a sample of surgically removed RCC tumors and human cell lines, a GnRHR overexpression was detected, and the use of GnRH antagonists inhibited tumor growth $(21,25)$. FSHR has also been found to be overexpressed in the RCC endothelium, and their stimulation accelerates neovascularization, possibly by inducing vascular endothelial growth factor (VEGF) expression (26). Additionally, the periphery and luminal location of FSHR within the RCC tumor has been linked to the promotion of intravasation and, therefore, metastatic potential $(26,27)$. Furthermore, FSHR expression has been identified as a positive predictive marker of tumor response to the antitumor drug sunitinib (28).

Estrogens play vital physiological roles in the body through two different estrogen receptors, ER- $\alpha$ and ER- $\beta$ (29,30), that appeared to be controlled by gonadotropins $(31,32)$. The biological functions of ER- $\alpha$ and ER- $\beta$ are different (33). In normal conditions, their function maintains a homeostatic balance (34). However, this balance appears to be disrupted in tumors (34). It has been suggested that ER- $\alpha$ and ER- $\beta$ present with variable expressions in RCC cells that may affect the prognosis and outcome of the disease $(21,35,36)$. The ER- $\alpha$ gene is considered to play a role as a tumor promoter in RCC by increasing the transcription of growth-related factors that regulate the activation of downstream genes, leading to carcinogenesis $(21,33,34)$. A variant of ER- $\alpha, E R-\alpha 36$, was previously identified in RCC and may play a role in the progression of RCC (37). Despite the previous belief that ER- $\beta$ has a tumor-suppressive effect on RCC, recent studies have shown the opposite (38-40). Genomic analysis of clinical samples from RCC patients revealed that high expression of ER- $\beta$ was associated with a more advanced stage and a worse prognosis, including shorter overall survival and disease-free survival (38). ER- $\beta$ enhances tumor growth and invasion by regulating HOTAIR expression, a crucial long non-coding RNA (lncRNA) with oncogenic effect (38). HOTAIR downregulates the expression of several microRNAs (miRNA) with tumor suppressor roles, including miR-138, $-204,-217$ by direct antagonization and $\mathrm{miR}-200 \mathrm{c}$ by epigenetic modulation, as well upregulates various oncogenes, including VEGFA and EZH2, that promote RCC progression (38).

Many advances in treating progressive and advanced RCC disease, targeting different tumor processes, have evolved over recent years (41). Inhibition of hormonal signaling may thus play a putative role in supportive therapies against this cancer. So far, some attempts to target ER and other sex-hormone receptors as an adjunctive treatment of RCC have had some promissory effects $(21,42,43)$. 
To our knowledge, this is the first time that a case of ovarian stimulation therapy has been linked to RCC development. Although sex hormones may play a significant role in the pathophysiology of RCC, no study has investigated the possible effect of hormonal therapy and, in particular controlled ovarian stimulation therapy, on the development of RCC. Although epidemiological studies have not shown a clear association between controlled ovarian stimulation and $\mathrm{RCC}$, given the increasing number of patients receiving these treatments, further study is needed, including a larger number of patients and longer follow-up. We believe that a large observational study with long-term follow-up will clarify the association between RCC development and the use of sex hormones in women undergoing controlled ovarian stimulation therapy.

In general, similar to our case, in patients with clinical suspicion, either CT or MRI imaging is the first step in evaluating renal cell carcinoma. In isolated mass cases, partial or total nephrectomy is preferred compared to biopsy because it can provide more information for tumor staging (44).

The determination of hormone receptors in $\mathrm{RCC}$ is not commonly performed. Foersch et al (45), in a recent study, suggested that the androgen receptor expression might be associated with a favorable prognosis. On the other hand, El-Deek et al (36), showed that high cytoplasmic ER levels lead to shorter overall survival and disease-free survival, suggesting the prognostic value of the ER expression as an indicator of poor prognosis. The expression of sex-hormone receptors in the patient's tumor involved in this case was not measured due to financial constraints. We suggest that measuring sex-hormone expression in documented clear cell RCC in large-scale clinical studies will provide valuable prognostic and diagnostic information, as well as aid in the development of new potential adjuvant therapies.

In conclusion, recent data support that sex hormones and their receptors have an important role in RCC pathophysiology, suggesting that the presence of excess hormones in patients could increase the risk for RCC. In this case, we raise awareness of the need for more systematic research to clarify the potential oncogenic effect of controlled ovarian stimulation therapy and the clinical significance of the existing pre-clinical data.

\section{Acknowledgements}

Not applicable.

\section{Funding}

No funding was received.

\section{Availability of data and materials}

The datasets used and/or analyzed during the current study are available from the corresponding author on reasonable request.

\section{Authors' contributions}

All the authors (SGD, BM, MER and DPV) were involved in conceiving and designing the study. SGD and BM contributed to patient data collection. SGD, BM and MER confirmed the authenticity of all the raw data. SGD, BM and MER contributed to interpretation of data. SGD, BM, MER and DPV involved in the preparation of the original draft. SGD and DPV critically revised the manuscript. All authors have read and approved the final version of the manuscript.

\section{Ethics approval and consent to participate}

The hospital to which the patient was admitted is a teaching hospital, and all patients signed a written consent for participation and publication of their associated data.

\section{Patient consent for publication}

The patient provided oral and written approval for participation and publication of the information presented in the current study. All identifying information was removed.

\section{Competing interests}

The authors declare that they have no competing interests.

\section{References}

1. GLOBOCAN: The GlobalCancer Observatory.https://gco.iarc.fr/. Accessed July 1, 2020.

2. Znaor A, Lortet-Tieulent J, Laversanne M, Jemal A and Bray F: International variations and trends in renal cell carcinoma incidence and mortality. Eur Urol 67: 519-530, 2015.

3. Chow WH, Dong LM and Devesa SS: Epidemiology and risk factors for kidney cancer. Nat Rev Urol 7: 245-257, 2010.

4. Jemal A, Clegg LX, Ward E, Ries LA, Wu X, Jamison PM, Wingo PA, Howe HL, Anderson RN and Edwards BK: Annual report to the nation on the status of cancer, 1975-2001, with a special feature regarding survival. Cancer 101: 3-27, 2004.

5. Low G, Huang G, Fu W, Moloo Z and Girgis S: Review of renal cell carcinoma and its common subtypes in radiology. World $\mathrm{J}$ Radiol 8: 484-500, 2016.

6. Salmond JM: Pathology of tumours of the kidney and urinary tract. Surgery (Oxford) 37: 481-486, 2019.

7. Escudier B, Porta C, Schmidinger M, Rioux-Leclercq N, Bex A, Khoo V, Grünwald V, Gillessen S and Horwich A; ESMO Guidelines Committee: Renal cell carcinoma: ESMO Clinical Practice Guidelines for diagnosis, treatment and follow-up. Ann Oncol 30: 706-720, 2019.

8. Chandra A, Copen CE and Stephen EH: Infertility and impaired fecundity in the United States, 1982-2010: Data from the National Survey of Family Growth. Natl Health Stat Report 1-18, 2013.

9. Chandra A, Copen CE and Stephen EH: Infertility service use in the United States: Data from the National Survey of Family Growth, 1982-2010. Natl Health Stat Rep 1-21, 2014.

10. Quaas AM and Legro RS: Pharmacology of medications used for ovarian stimulation. Best Pract Res Clin Endocrinol Metab 33: 21-33, 2019.

11. Gibreel A and Bhattacharya S: Recombinant follitropin alfa/lutropin alfa in fertility treatment. Biologics 4: 5-17, 2010.

12. Tarlatzis BC, Zepiridis L, Grimbizis G and Bontis J: Clinical management of low ovarian response to stimulation for IVF: A systematic review. Hum Reprod Update 9: 61-76, 2003.

13. Check JH, Wilson C, Cohen R, Choe JK and Corley D: Mid-luteal phase injection of subcutaneous leuprolide acetate improves live delivered pregnancy and implantation rates in younger women undergoing in vitro fertilization-embryo transfer (IVF-ET). Clin Exp Obstet Gynecol 42: 427-428, 2015.

14. Eftekhar M, Bagheri RB, Neghab N and Hosseinisadat R: Evaluation of pretreatment with Cetrotide in an antagonist protocol for patients with PCOS undergoing IVF/ICSI cycles: A randomized clinical trial. JBRA Assist Reprod 22: 238-243, 2018. 
15. Serour GI, Aboulghar M, Mansour R, Sattar MA, Amin Y and Aboulghar H: Complications of medically assisted conception in 3,500 cycles. Fertil Steril 70: 638-642, 1998.

16. Li LL, Zhou J, Qian XJ and Chen YD: Meta-analysis on the possible association between in vitro fertilization and cancer risk. Int J Gynecol Cancer 23: 16-24, 2013.

17. Rizzuto I, Behrens RF and Smith LA: Risk of ovarian cancer in women treated with ovarian stimulating drugs for infertility. Cochrane Database Syst Rev 6: CD008215, 2019.

18. Dor J, Lerner-Geva L, Rabinovici J, Chetrit A, Levran D, Lunenfeld B, Mashiach S and Modan B: Cancer incidence in a cohort of infertile women who underwent in vitro fertilization. Fertil Steril 77: 324-327, 2002

19. Brinton LA, Scoccia B, Moghissi KS, Westhoff CL, Althuis MD, Mabie JE and Lamb EJ: Breast cancer risk associated with ovulation-stimulating drugs. Hum Reprod 19: 2005-2013, 2004.

20. Gauthier E, Paoletti X and Clavel-Chapelon F; E3N group: Breast cancer risk associated with being treated for infertility: Results from the French E3N cohort study. Hum Reprod 19: 2216-2221, 2004.

21. Czarnecka AM, Niedzwiedzka M, Porta C and Szczylik C: Hormone signaling pathways as treatment targets in renal cell cancer (Review). Int J Oncol 48: 2221-2235, 2016.

22. Concolino G, Marocchi A, Conti C, Tenaglia R, Di Silverio F and Bracci U: Human renal cell carcinoma as a hormone-dependent tumor. Cancer Res 38: 4340-4344, 1978.

23. Zucchetto A, Talamini R, Dal Maso L, Negri E, Polesel J, Ramazzotti V, Montella M, Canzonieri V, Serraino D, La Vecchia C and Franceschi S: Reproductive, menstrual, and other hormone-related factors and risk of renal cell cancer. Int J Cancer 123: 2213-2216, 2008.

24. Bennett NC, Rajandram R, Ng KL and Gobe GC: Evaluation of steroid hormones and their receptors in development and progression of renal cell carcinoma. J Kidney Cancer VHL 1: $17-25,2014$.

25. Keller G, Schally AV, Gaiser T, Nagy A, Baker B, Halmos G and Engel JB: Receptors for luteinizing hormone releasing hormone expressed on human renal cell carcinomas can be used for targeted chemotherapy with cytotoxic luteinizing hormone releasing hormone analogues. Clin Cancer Res 11: 5549-5557, 2005.

26. Radu A, Pichon C, Camparo P, Antoine M, Allory Y, Couvelard A, Fromont G, Hai MT and Ghinea N: Expression of follicle-stimulating hormone receptor in tumor blood vessels. $\mathrm{N}$ Engl J Med 363: 1621-1630, 2010.

27. Siraj A, Desestret V, Antoine M, Fromont G, Huerre M, Sanson M, Camparo P, Pichon C, Planeix F, Gonin J, et al: Expression of follicle-stimulating hormone receptor by the vascular endothelium in tumor metastases. BMC Cancer 13: 246, 2013.

28. Siraj MA, Pichon C, Radu A and Ghinea N: Endothelial follicle stimulating hormone receptor in primary kidney cancer correlates with subsequent response to sunitinib. J Cell Mol Med 16: 2010-2016, 2012.

29. Paterni I, Granchi C, Katzenellenbogen JA and Minutolo F: Estrogen receptors alpha $(\mathrm{ER} \alpha)$ and beta $(\mathrm{ER} \beta)$ : Subtype-selective ligands and clinical potential. Steroids 90: 13-29, 2014.

30. Lee HR, Kim TH and Choi KC: Functions and physiological roles of two types of estrogen receptors, ER $\alpha$ and ER $\beta$, identified by estrogen receptor knockout mouse. Lab Anim Res 28: 71-76, 2012.
31. Kouzu-Fujita M, Mezaki Y, Sawatsubashi S, Matsumoto T, Yamaoka I, Yano T, Taketani Y, Kitagawa $\mathrm{H}$ and Kato S: Coactivation of estrogen receptor $\beta$ by gonadotropin-induced cofactor GIOT-4. Mol Cell Biol 34: 919, 2014.

32. Chen J, An BS, Cheng L, Hammond GL and Leung PC: Gonadotropin-releasing hormone-mediated phosphorylation of estrogen receptor-alpha contributes to fosB expression in mouse gonadotrophs. Endocrinology 150: 4583-4593, 2009.

33. Speirs V, Skliris GP, Burdall SE and Carder PJ: Distinct expression patterns of ER alpha and ER beta in normal human mammary gland. J Clin Pathol 55: 371-374, 2002.

34. Chen GG, Zeng Q and Tse GM: Estrogen and its receptors in cancer. Med Res Rev 28: 954-974, 2008.

35. Thomas $\mathrm{C}$ and Gustafsson JA: The different roles of ER subtypes in cancer biology and therapy. Nat Rev Cancer 11: 597-608, 2011

36. El-Deek HE, Ahmed AM, Hassan TS and Morsy AM Expression and localization of estrogen receptors in human renal cell carcinoma and their clinical significance. Int J Clin Exp Pathol 11: 3176-3185, 2018.

37. Wang Q, Zhang W, Yang J, Liu YL, Yan ZX, Guo ZJ, Li YJ and Bian XW: High ER 36 expression level and membrane location predict poor prognosis in renal cell carcinoma. Medicine (Baltimore) 94: e1048, 2015.

38. Ding J, Yeh CR, Sun Y,LinC,Chou J, OuZ, Chang C, Qi J and Yeh S: Estrogen receptor $\beta$ promotes renal cell carcinoma progression via regulating LncRNA HOTAIR-miR-138/200c/204/217 associated CeRNA network. Oncogene 37: 5037-5053, 2018.

39. Pan Y, Wu Y, Hu J, Shan Y, Ma J, Ma H, Qi X and Jia L: Long noncoding RNA HOTAIR promotes renal cell carcinoma malignancy through alpha-2, 8 -sialyltransferase 4 by sponging microRNA-124. Cell Prolif 51: e12507, 2018.

40. Hong Q, Li O, Zheng W, Xiao WZ, Zhang L, Wu D, Cai GY, He JC and Chen XM: LncRNA HOTAIR regulates HIF-1 $\alpha / A X L$ signaling through inhibition of miR-217 in renal cell carcinoma. Cell Death Dis 8: e2772, 2017.

41. Pircher A, Wolf D, Heidenreich A, Hilbe W, Pichler R and Heidegger I: Synergies of targeting tumor angiogenesis and immune checkpoints in non-small cell lung cancer and renal cell cancer: From basic concepts to clinical reality. Int J Mol Sci 18: 2291, 2017

42. Song W, He D, Chen Y, Yeh CR, Hsu I, Huang Q, Zhang X, Chang LS, Zuo L, Chen J, et al: Targeting newly identified ER $\beta /$ TGF- $\beta 1 /$ SMAD3 signals with the FDA-approved anti-estrogen Faslodex or an ER $\beta$ selective antagonist in renal cell carcinoma. Mol Oncol 12: 2055-2071, 2018.

43. Gu J, Zhang Y, Han Z, Gao L, Cui J, Sun Y, Niu Y, You B, Huang CP, Chang C, et al: Targeting the ER $\beta /$ Angiopoietin- $2 /$ Tie-2 signaling-mediated angiogenesis with the FDA-approved anti-estrogen Faslodex to increase the Sunitinib sensitivity in RCC. Cell Death Dis 11: 367, 2020.

44. Chevinsky M, Imnadze M, Sankin A, Winer A, Mano R, Jakubowski C, Mashni J, Sjoberg DD, Chen YB, Tickoo SK, et al: Pathological stage T3a significantly increases disease recurrence across all tumor sizes in renal cell carcinoma. J Urol 194: 310-315, 2015.

45. Foersch S, Schindeldecker M, Keith M, Tagscherer KE, Fernandez A, Stenzel PJ, Pahernik S, Hohenfellner M, Schirmacher P, Roth W and Macher-Goeppinger S: Prognostic relevance of androgen receptor expression in renal cell carcinomas. Oncotarget 8: 78545-78555, 2017. 